\title{
PERBANDINGAN BIAYA DAN WAKTU PEKERJAAN DINDING PASANGAN BATA MERAH DAN BATU KUMBUNG PERUMAHAN GRIYA PERMATA INSANI
}

\author{
Mashudin $^{1)}$, Rasio Hepiyanto ${ }^{2)}$ \\ ${ }^{1)}$ Program Studi Teknik Sipil Universitas Islam Lamongan \\ ${ }^{2)}$ Fakultas Teknik Prodi Teknik Sipil Universitas Islam Lamongan \\ email:mashudin14@gmail.com,waringinmegah_rasio@yahoo.com
}

\begin{abstract}
Contruction expanded rapidly and spread in Lamongan, from fairly simple residential contractor to large developer continuing to explore in building construction. This research aims to know the comparative costs of wall job using material white brick and red brick based on analysis of a contractor with the methodof 2017 SNI job and time of wall job white brick and red brick per $\mathrm{m}^{2}$ using method Daily Record Sheet that is by direct observation and recording work time couples wall field. The result of the research conducted is found the cost of work required for couples wallwhite stone per $\mathrm{m}^{2}$ using analysis of contractor is $R p .66 .020,-/ \mathrm{m}^{2}$ and a pairof red brick wall is Rp. 75.020,- $/ \mathrm{m}^{2}$. The cost of the work required for the pair of wall stone kumbung per $m^{2}$ based on SNI method 2017 is Rp. 109.910, $-\mathrm{Im}^{2}$ and pair of red brick wall is Rp. 113.100,- $/ \mathrm{m}^{2}$. After the comparison then it can be inferred that the couple wall using white brick cheaper than the pair of red brick wall, but the difference is not too significant is Rp 9,000,-per $m^{2}$ with contractor method and IDR 3,190,-per $\mathrm{m}^{2}$ using SNI 2017method. The time it takes to complete the job of couple wall using red brick per $m 2$ is 0.445 hours $/ \mathrm{m}^{2}$, whereas the time required on the job of couple wall using white brick is 0.324 hours $\mathrm{m}^{2}$. So the job of the couple wall using white brick more efficient 0.121 hours $/ \mathrm{m}^{2}$ compared with red brick wall.
\end{abstract}

Keywords: RAB, job of wall, white brick, red brick.

\section{PENDAHULUAN}

Pembangunan terus berkembang dengan cepat dan menyebar di Lamogan, dari kontraktor rumah tinggal yang cukup sederhana sampai pengembang-pengembang besar yang terus bereksplorasi dalam konstruksi bangunan. Hal ini menjadi dasar terjadinya alternatif dalam suatu bidang, alternatif yang ikut terjadi pada pekerjaan dinding.

Dinding pada umumnya disusun dengan menggunakan bata merah. Akan tetapi, pada beberapa dekade ini terjadi perkembangan pada material dinding, munculnya bata ringan yang merupakan material baru sebagai alternatif pengganti bata merah pada konstruksi dinding. Inovasi bata ringan ini dikenal karena lebih cepat, namun untuk kontraktor perumahan griya permatainsani bata ringan ini masih terlalu mahal dikarenakan ukuran rumah yang akan di bangun di perumahan tersebut terbilang kecil. Hal ini yang menjadi dasar adanya alternatif lain selain batu bata merah dan bata ringan untuk bahan pasangan dinding yaitu batu kumbung.Tujuan yang ingin dicapai dari penelitian ini adalah Untuk mengetahui, dari kedua bahan (Bata merah dan Batu kumbung) dalam pekerjaan dinding yang lebih murah biayanya per $\mathrm{m}^{2}$ dan untuk mengetahui, waktu yang dibutuhkan dalam menyelesaikan pemasangan dinding bata merah dan dinding batu kumbung per $\mathrm{m}^{2}$.

\section{METODE PENELITIAN}

\section{Lokasi Penelitian}

Wilayah penelitian dilakukan pada pembangunan Perumahan Griya Permata Insani yang berlokasi di Jl. Raya Mantup Lamongan, Kec. Tikung, Kab. Lamongan. Pelaksanaan penelitian hanya dilakukan pada pekerjaan konstruksi dinding.

\section{Teknik Pengumpulan Data}

Teknik pengumpulan data pada penelitian ini adalah dengan metode analisa RAB 
kontraktor dan metode SNI 2017 untuk mengetahui biaya pekerjaan pasangan dinding per $\mathrm{m}^{2}$ dan observasi untuk menghitung waktu pekerjaan pasangan dinding per $\mathrm{m}^{2}$.

\section{Bagan Alir Penelitian}

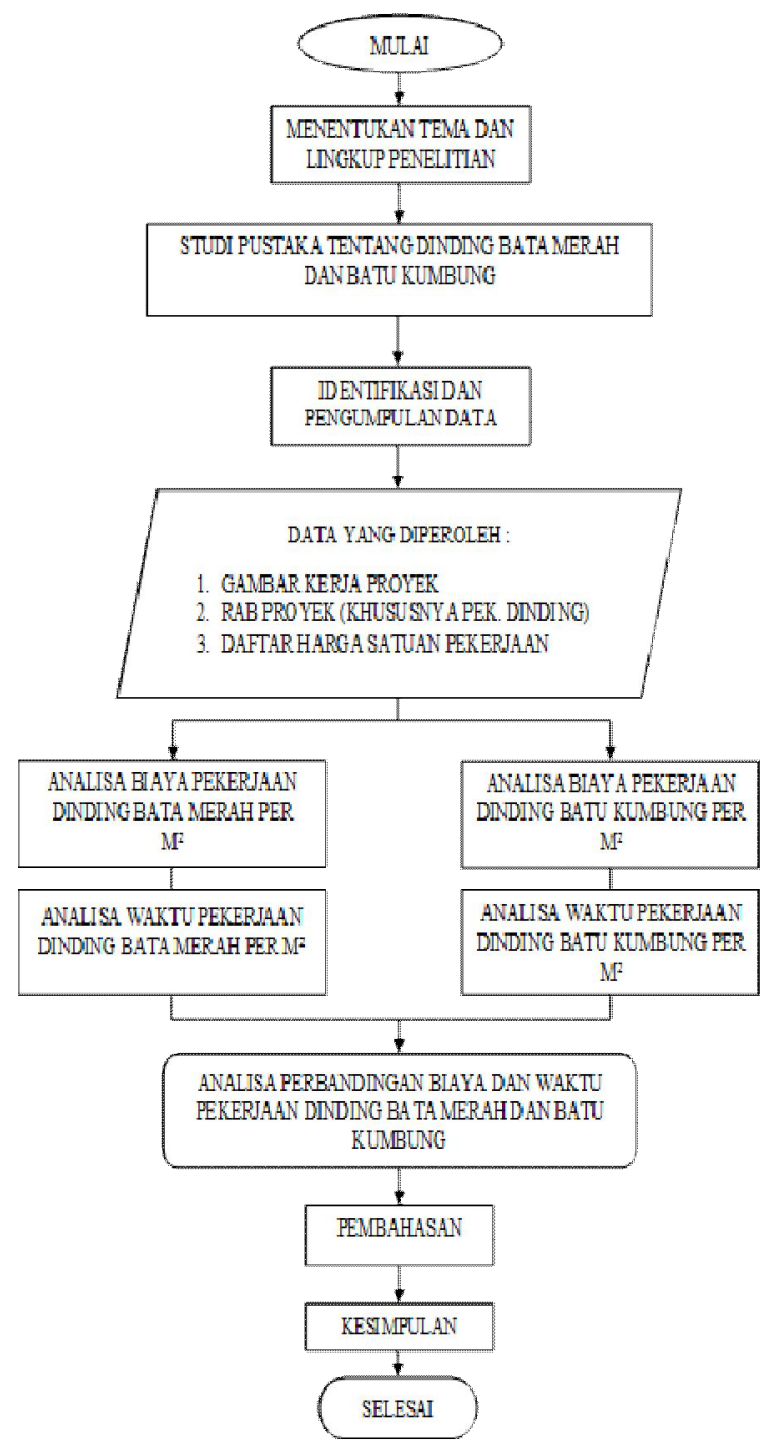

Gambar 1. Bagan Alir Penelitian

\section{Perhitungan Biaya Pekerjaan Dinding}

Biaya pekerjaan adalah besarnya anggaran yang digunakan atau dikeluarkan untuk pekerjaan dinding tersebut. Adapun data yang diperlukan untuk menghitung biaya pekerjaan dinding adalah harga bahan dan harga upah pekerjaan pasangan dinding.

\section{Perhitungan Waktu Pekerjaan Dinding}

Waktu pekerjaan adalah lamanya durasi pekerjaan yang dihasilkan dalam suatu pekerjaan. Untuk mengetahui lamanya durasi pekerjaan pasangan dinding menggunakan bata merah dan batu kumbung per $\mathrm{m}^{2}$ penulis melakukan observasi ke lapangan untuk mencatat semua aktifitas pemasangan dinding. Metode yang digunakan untuk menghitung durasi pekerjaan adalah daily record sheet (lembar catatan harian) atau produktivitas harian. Volume dari pekerjaan yang dihasilkan pada hari itu dibagi dengan waktu kerja yang dirumuskan sebagai berikut :

Daily Productivity $=\frac{\text { Daily Quantity }}{\text { Daily Work Hours }} \times 7$ Hours

\section{HASIL DAN PEMBAHASAN}

Dari hasil penelitian yang telah dilakukan dan di analisa didapatkan biaya bahan untuk pasangan dinding menggunakan batu kumbung dan biaya dinding menggunakan bata merah dengan perbandingan menggunakan analisa kontraktor dan metode SNI 2017.

\section{Biaya Pekerjaan Dinding Batu Kumbung dan Bata Merah Analisa Kontraktor}

Rekapitulasi biaya pekerjaan dinding batu kumbung

Total biaya pekerjaan $1 \mathrm{~m}^{2}$ dinding batu kumbung dengan perbandingan spesi 1 PC : 5 PP adalah sebagai berikut :

Tabel 1. Biaya Pekerjaan Dinding Batu Kumbung Analisa Kontraktor

\begin{tabular}{cccc}
\hline No & \multicolumn{1}{c}{ Uraian } & \multicolumn{2}{c}{ Jumlah Harga } \\
\hline $\mathbf{1}$ & Harga Bahan & Rp. & 43.620 \\
\hline $\mathbf{2}$ & Upah Tenaga Kerja & Rp. & 22.400 \\
\hline & Total & Rp. & $\mathbf{6 6 . 0 2 0}$ \\
\hline Sumber : Kontraktor & &
\end{tabular}

Dari tabel 1 diatas biaya yang dibutuhkan untuk pekerjaan $1 \mathrm{~m}^{2}$ dinding batu kumbung berdasarkan analisa kontraktor adalah senilai Rp. 66.020,-

Total biaya pekerjaan $1 \mathrm{~m}^{2}$ dinding bata merah dengan perbandingan spesi $1 \mathrm{PC}: 5 \mathrm{PP}$ adalah sebagai berikut : 
Tabel 2. Biaya Pekerjaan Dinding Bata Merah Analisa Kontraktor

\begin{tabular}{clrl}
\hline No & \multicolumn{1}{c}{ Uraian } & \multicolumn{2}{c}{ Jumlah Harga } \\
\hline $\mathbf{1}$ & Harga Bahan & Rp. & 52.620 \\
\hline $\mathbf{2}$ & Upah Tenaga Kerja & Rp. & 22.400 \\
& Total & Rp. & $\mathbf{7 5 . 0 2 0}$
\end{tabular}

Sumber : Kontraktor

Dari tabel 2 diatas biaya yang dibutuhkan untuk pekerjaan $1 \mathrm{~m}^{2}$ dinding bata merah berdasarkan analisa kontraktor adalah senilai Rp. 75.020,-

\section{Biaya Pekerjaan Dinding Batu Kumbung dan Bata Merah Metode SNI 2017}

Rekapitulasi Biaya Pekerjaan Dinding Batu Kumbung

Total biaya pekerjaan $1 \mathrm{~m}^{2}$ dinding batu kumbung dengan perbandingan spesi $1 \mathrm{PC}: 5$ PP adalah sebagai berikut :

Tabel 3. Biaya Pekerjaan Dinding Batu Kumbung Metode SNI 2017

\begin{tabular}{clcc}
\hline No & \multicolumn{1}{c}{ Uraian } & \multicolumn{2}{c}{ Jumlah Harga } \\
\hline $\mathbf{1}$ & Harga Bahan & Rp. & 78.085 \\
\hline $\mathbf{2}$ & Upah Tenaga Kerja & Rp. & 31.825 \\
\hline & Total & Rp. & $\mathbf{1 0 9 . 9 1 0}$ \\
\hline
\end{tabular}

Sumber : SNI 2017

Dari tabel 3 diatas diketahui biaya yang dibutuhkan untuk pekerjaan $1 \mathrm{~m}^{2}$ dinding batu kumbung menggunakan metode SNI 2017 adalah senilai Rp.109.910,-

Total biaya pekerjaan $1 \mathrm{~m}^{2}$ dinding bata merah dengan perbandingan spesi 1 PC : 5 PP adalah sebagai berikut :

Tabel 4. Biaya Pekerjaan Dinding Bata Merah Metode SNI 2017

\begin{tabular}{clcc}
\hline No & \multicolumn{1}{c}{ Uraian } & \multicolumn{2}{c}{ Jumlah Harga } \\
\hline $\mathbf{1}$ & Harga Bahan & Rp. & 81.275 \\
$\mathbf{2}$ & Upah Tenaga Kerja & Rp. & 31.825 \\
\hline & Total & Rp. & $\mathbf{1 1 3 . 1 0 0}$
\end{tabular}

Sumber : SNI 2017

Dari tabel 4 diatas didapatkan biaya yang dibutuhkan untuk pekerjaan $1 \mathrm{~m}^{2}$ dinding bata merah dengan metode SNI 2017 adalah senilai Rp. 113.100,--

\section{Perbandingan Biaya Pekerjaan Dinding Batu Kumbung dan Bata Merah}

Perbandingan biaya pekerjaan dinding analisa kontraktor

Tabel 5. Selisih Biaya Batu Kumbung dan Bata Merah Analisa Kontraktor

\begin{tabular}{|c|c|c|c|c|}
\hline No & $\begin{array}{c}\text { Jenis } \\
\text { Material }\end{array}$ & $\begin{array}{c}\text { Batu } \\
\text { Kumbung/m }{ }^{2}\end{array}$ & $\begin{array}{c}\text { Bata } \\
\text { Merah/m } \mathbf{m}^{2}\end{array}$ & Selisih $/ \mathrm{m}^{2}$ \\
\hline 1 & $\begin{array}{l}\text { Pasangan } \\
\text { Bata }\end{array}$ & Rp. 36.200 & Rp. 45.200 & Rp. 9.000 \\
\hline 2 & $\begin{array}{l}\text { Plesteran } \\
+ \text { Aci }\end{array}$ & Rp. 7.420 & Rp. 7.420 & - \\
\hline & TOTAL & Rp. 43.620 & Rp. 52.620 & Rp. 9.000 \\
\hline
\end{tabular}

Sumber : Hasil Perhitungan

Dari tabel 5 diatas dapat disimpulkan bahwa batu kumbung sebagai bahan dinding lebih murah dari bata merah dengan selisih harga Rp. $9000 / \mathrm{m}^{2}$ Perbandingan biaya pekerjaan dinding analisa SNI 2017.

Tabel 6. Selisih Biaya Batu Kumbung dan Bata Merah Metode SNI 2017

\begin{tabular}{|c|c|c|c|c|}
\hline No & $\begin{array}{c}\text { Jenis } \\
\text { Material }\end{array}$ & $\begin{array}{c}\text { Batu } \\
\text { Kumbung/m² }\end{array}$ & $\begin{array}{c}\text { Bata } \\
\text { Merah/m² }\end{array}$ & Selisih $/ \mathrm{m}^{2}$ \\
\hline 1 & $\begin{array}{l}\text { Pasangan } \\
\text { Bata }\end{array}$ & Rp. 57.925 & Rp. 61.115 & Rp. 3.190 \\
\hline 2 & $\begin{array}{l}\text { Plesteran } \\
+ \text { Aci }\end{array}$ & Rp. 20.160 & Rp. 20.160 & - \\
\hline & TOTAL & Rp. 78.085 & Rp. 81.275 & Rp. 3.190 \\
\hline
\end{tabular}

Sumber : Hasil Perhitungan

Dari tabel 6 diatas dapat disimpulkan bahwa batu kumbung sebagai bahan dinding lebih murah dari bata merah dengan selisih harga Rp. $3.190 / \mathrm{m}^{2}$.

Jadi dapat disimpulkan bahwa pekerjaan dinding menggunakan batu kumbung lebih murah dari bata merah meskipun analisa yang digunakan berbeda, yaitu dari analisa kontraktor maupun metode SNI 2017.

\section{Perbandingan Biaya Pekerjaan Dinding Analisa Kontraktor dan SNI 2017}

Dibawah ini adalah rekapitulasi perbandingan hasil perhitungan harga satuan pekerjaan dinding yang dilakukan kontraktor dan dengan perhitungan menggunakan metode SNI 2017 
Tabel 7. Perbandingan Biaya Pekerjaan Dinding Kontraktor dan SNI 2017

HARGA SATUAN

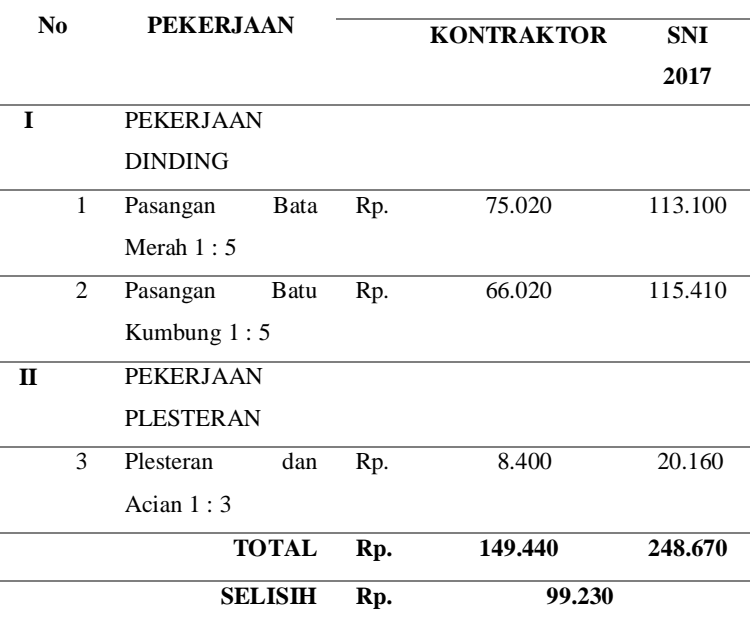

Sumber : Hasil Perhitungan

Dari Tabel 7 Terlihat nilai total harga satuan pekerjaan dinding yang dihasilkan pada perhitungan Kontraktor lebih kecil Rp. 149.440,- dari pada perhitungan dengan analisa SNI 2017 sebesar Rp. 248.670,- .

Sedangkan di bawah ini merupakan grafik hasil perbandingan harga satuan yang dilakukan kontraktor dengan perhitungan menggunakan SNI 2017.

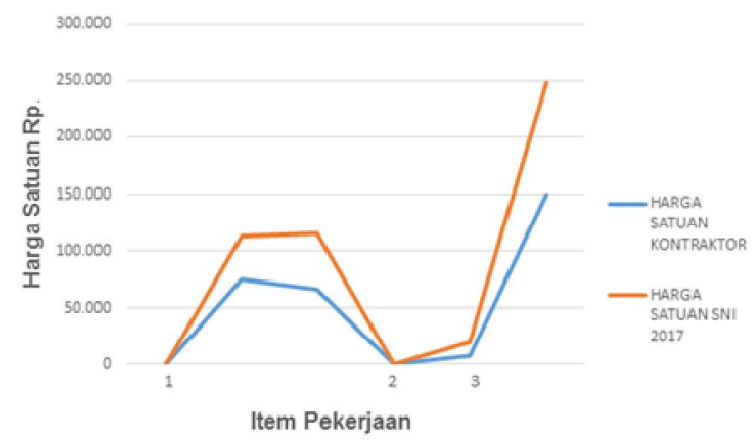

Sumber : Hasil Analisa Perbandingan

Gambar 2. Perbandingan Metode SNI 2017 dan Kontraktor

(Dari Item pekerjaan Tabel 7)

Terlihat semua nilai harga satuan pada tiga item pekerjaan yang dihasilkan dari perhitungan kontraktor lebih kecil dari hasil perhitungan dengan metode SNI 2017.

Analisa Waktu Pekerjaan Dinding Batu kumbung dan Bata Merah

Analisa waktu pekerjaan dinding batu
Dari hasil pengamatan dilapangan langsung didapatkan produktivitas batu kumbung mempunyai nilai rata-rata $3,093 \mathrm{~m}^{2} / \mathrm{jam}$. Produktivitas rata-rata waktu yang dibutuhkan adalah 0,377 jam.

Perhitungan waktu pekerjaan dinding batu kumbung $1 \mathrm{~m}^{2}$ adalah :

Waktu pekerjaan dinding batu kumbung $/ \mathrm{m}^{2}$

$$
\begin{aligned}
& =\frac{1}{\text { Rata-rata produktivitas } \mathrm{m}^{2} / \mathrm{jam}} \\
& =\frac{1}{3,093 \mathrm{~m}^{2} / \mathrm{jam}} \\
& =\quad 0,324 \mathrm{jam}
\end{aligned}
$$

Agar lebih jelas maka dibuatkan tabel sebagai berikut :

Tabel 8. Waktu Pekerjaan Dinding Batu Kumbung

\begin{tabular}{lcccccc}
$\mathrm{N}$ & Jenis pengamatan & Produktivitas & Waktu & Luas & W x L & \\
\cline { 3 - 5 } & $(\mathrm{m} 2 / \mathrm{j} \mathrm{jm})$ & $(\mathrm{jam} / \mathrm{m} 2)$ & $(\mathrm{m} 2)$ & $(\mathrm{jam})$ & Hari \\
\hline & & & & & & \\
1 & Pasangan Dinding & 3,093 & 0,324 & 21 & 6,804 & 0,972
\end{tabular}

Sumber : Hasil Perhitungan Waktu Pekerjaan Dinding

Dari tabel 8 di atas menunjukkan produktivitas pekerjaan dinding batu kumbung adalah 3,093 $\mathrm{m}^{2} / \mathrm{jam}$ dan waktu yang dibutuhkan untuk pekerjaan dinding batu kumbung adalah 0,324 $\mathrm{jam} / \mathrm{m}^{2}$ dari luasan dinding $21 \mathrm{~m}^{2}$.

Analisa waktu pekerjaan dinding bata merah

Dari hasil pengamatan dilapangan langsung didapatkan produktivitas bata merah mempunyai nilai rata-rata $2,248 \mathrm{~m}^{2} / \mathrm{jam}$. Produktivitas rata-rata waktu yang dibutuhkan adalah 0,541 jam.

Perhitungan waktu pekerjaan dinding bata merah $1 \mathrm{~m}^{2}$ adalah :

Waktu pekerjaan dinding bata merah $/ \mathrm{m}^{2}$

$=$ $\frac{1}{\text { Rata-rata produktivitas } \mathrm{m}^{2} / \mathrm{jam}}$

$$
\begin{aligned}
& =\frac{1}{2,248 \mathrm{~m}^{2} / \mathrm{jam}} \\
& =\quad 0,445 \mathrm{jam}
\end{aligned}
$$


Tabel 9. Waktu Pekerjaan Dinding Bata Merah

\begin{tabular}{|c|c|c|c|c|c|c|}
\hline \multirow[t]{2}{*}{$\mathrm{N}$} & \multirow[t]{2}{*}{ Jenis pengamatan } & Produktivitas & Waktu & Luas & $\mathrm{W} \times \mathrm{L}$ & \multirow{2}{*}{ Hari } \\
\hline & & (m2/jam) & $(\mathrm{jam} / \mathrm{m} 2)$ & (m2) & (jam) & \\
\hline 1 & Pasangan Dinding & 2,248 & 0,445 & 21 & 9,345 & 1,34 \\
\hline
\end{tabular}

Sumber : Hasil Perhitungan Waktu Pekerjaan Dinding

Dari tabel 9 di atas menunjukkan produktivitas pekerjaan dinding bata merah adalah 2,248 $\mathrm{m}^{2} / \mathrm{jam}$ dan waktu yang dibutuhkan untuk pekerjaan dinding bata merah adalah 0,324 $\mathrm{jam} / \mathrm{m}^{2}$ dari luasan dinding $21 \mathrm{~m}^{2}$.

\section{Perbandingan waktu pekerjaan dinding batu kumbung dan bata merah}

Selanjutnya dilakukan perbandingan agar diketahui bahan mana diantara batu kumbung dan bata merah yang mempunyai waktu lebih cepat per $\mathrm{m}^{2}$.

Tabel 10. Perbandingan Waktu Pekerjaan Dinding

\begin{tabular}{|c|c|c|c|}
\hline \multirow{2}{*}{ No } & \multirow{2}{*}{ Jenis Material } & Produktivitas & Waktu \\
\hline & & $\left(\mathrm{m}^{2} / \mathrm{jam}\right)$ & $\left(\mathbf{j a m} / \mathrm{m}^{2}\right)$ \\
\hline 1 & Pasangan Dinding Bata Merah & 2,248 & 0,445 \\
\hline 2 & Pasangan Dinding Batu Kumbung & 3,093 & 0,324 \\
\hline & Selisih Total & 0,845 & $\mathbf{0 , 1 2 1}$ \\
\hline
\end{tabular}

Sumber : Hasil Perbandingan Waktu Pekerjaan Dinding

Dari tabel 10 diatas didapatkan perbandingan produktivitas pekerjaan dinding menggunakan pasangan batu kumbung dan bata merah. Untuk selisih produktivitas pekerjaan adalah sebesar $0,845 \mathrm{~m}^{2} / \mathrm{jam}$, sedangkan untuk selisih waktu pekerjaan adalah $0,121 \mathrm{jam} / \mathrm{m}^{2}$. Dari perbandingan tersebut dapat disimpulkan bahwa pekerjaan dinding menggunakan batu kumbung lebih efisien waktu daripada menggunakan bata merah.

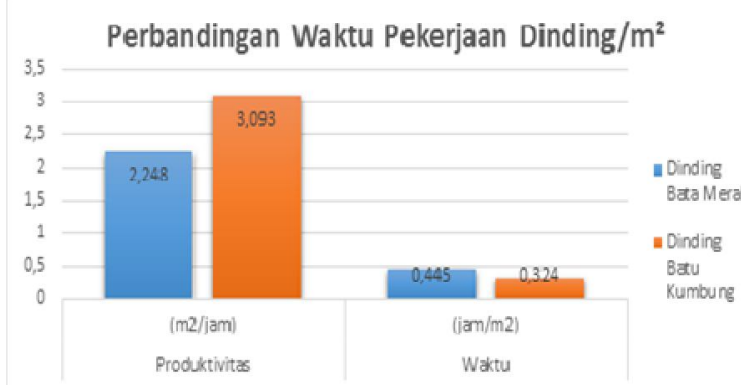

Sumber : Hasil Analisa Perbandingan Waktu Pekerjaan Dinding

Gambar 3. Perbandingan Waktu Pekerjaan Dinding
Dari grafik diatas dapat diketahui produktivitas pekerjaan dinding batu kumbung adalah 3,093 $\mathrm{m}^{2} /$ jam sedangkan produktivitas bata merah adalah $2,248 \mathrm{~m}^{2} / \mathrm{jam}$. Sedangkan waktu yang dibutuhkan untuk pekerjaan dinding batu kumbung adalah $0,324 \mathrm{jam} / \mathrm{m}^{2}$ dan waktu yang dibutuhkan untuk pekerjaan dinding bata merah adalah $0,445 \mathrm{jam} / \mathrm{m}^{2}$.

\section{KESIMPULAN}

Setelah melakukan serangkaian perhitungan dan pengamatan langsung dilapangan, maka dapat diambil kesimpulan mengenai perbandingan biaya dan waktu pekerjaan pasangan dinding dengan menggunakan material batu kumbung dan pasangan dinding dengan menggunakan material bata merah adalah Biaya pekerjaan yang diperlukan untuk $1 \mathrm{~m}^{2}$ pasangan dinding batu kumbung menggunakan analisa kontraktor adalah sebesar Rp. 66.020 ,- dan pasangan dinding bata merah $1 \mathrm{~m}^{2}$ adalah sebesar Rp. 75.020 ,-. Biaya pekerjaan yang diperlukan untuk $1 \mathrm{~m}^{2}$ pasangan dinding batu kumbung berdasarkan metode SNI 2017 adalah sebesar Rp. 109.910,- dan pasangan dinding bata merah $1 \mathrm{~m}^{2}$ adalah sebesar Rp. 113.100,-. Setelah dibandingkan maka dapat disimpulkan bahwa pasangan dinding menggunakan batu kumbung lebih murah dibandingkan pasangan dinding bata merah, adapun perbedaannya tidak terlalu signifikan yaitu Rp. 9.000,- per $\mathrm{m}^{2}$ dengan metode kontraktor dan Rp. 3.190,- per $\mathrm{m}^{2}$ menggunakan metode SNI 2017 dan Waktu yang dibutuhkan dalam menyelesaikan pekerjaan pasangan dinding menggunakan bata merah per $\mathrm{m}^{2}$ adalah $0,445 \mathrm{jam} / \mathrm{m}^{2}$, sedangkan waktu yang dibutuhkan pada pekerjaan pasangan dinding menggunakan batu kumbung adalah $0,324 \mathrm{jam} / \mathrm{m}^{2}$.Sehingga pekerjaan pasangan dinding menggunakan batu kumbung lebih efisien $0,121 \mathrm{jam} / \mathrm{m}^{2}$ dibandingkan dengan pasangan dinding bata merah.

\section{SARAN}

Setelah penulis melaksanakan penelitian tugas akhir tentang perbandingan biaya dan waktu pekerjaan dinding menggunakan pasangan bata merah dan batu kumbung pada proyek perumahan permata griya insani, ada beberapa saran untuk penelitian selanjutnya :

1. Penelitian tentang keunggulan lain penggunaan material batu kumbung 
dan bata merah sebagai bahan pasangan dinding.

2. Untuk kedepannya jika ada yang akan melakukan penelitian lebih lanjut tentang perbandingan biaya dan waktu material Batu kumbung mungkin dapat mengguanakan metode pengukuran Work Sampling agar terlihat waktu efektif dan waktu yang terbuang dalam pemasangan material Batu kumbung.

Penelitian tentang efek terhadap suatu proyek dengan nilai produktivitas material batu kumbung yang lebih tinggi dari material bata merah agar kedepannya tujuan dari keberhasilan proyek konstruksi dapat tercapai yaitu tepat waktu, tepat biaya dan tepat mutu.

\section{DAFTAR PUSTAKA}

Andi, dkk. 2004. Analisa Produktifitas Pekerja Dengan Metode Work Sampling : Studi Kasus Pada Proyek X dan Y. Jurnal. Surabaya: Universitas Kristen Petra

Evan, H. 2012. Perbandingan Produktivitas Pekerjaan Pasangan Dinding Bata Ringan Dan Bata Merah Pada Proyek Perumahan Di Surabaya. Surabaya: Universitas Kristen Petra.

Felix, Hidayat. 2010. Studi Perbandingan Biaya Material Pekerjaan Pasangan Dinding Bata Ringan Dengan Bata Merah. Jurusan Teknik Sipil, Fakultas Teknik, Universitas Katolik Parahyangan

Harun, Mohamad. Analisa Produktifitas Tenaga Kerja Pada Pekerjaan Konstruksi Gedung. Surabaya

Mandani, Toma. 2010.Analisis Produktivitas Tenaga Kerja Pada Pekerjaan Pasangan Bata. Surakarta : Universitas Sebelas Maret

Ningrum, Diah Niken Kusuma. 2014. Analisa Perbandingan Produktivitas Pemasangan DInding M-PANEL dan Dinding Konvensional Batu Bata (Studi Kasus: Proyek Pembangunan Ruko Modern Arcade di Tangerang. Skripsi. Jakarta: Universitas Mercu Buana

Nur Sahid, Muh.\&Safi'i,Imam. 2012. Analisa Perbandingan Produktivitas Kerja Pada Pekerjaan Dinding Bata Konvensional Dengan DindingBlok Hebel.; Surakarta: Simposium Nasional RAPI XI FT UMS.
Sinugroho, Gesang, dkk. 1982. Bata Merah Sebagai Bahan Bangunan 